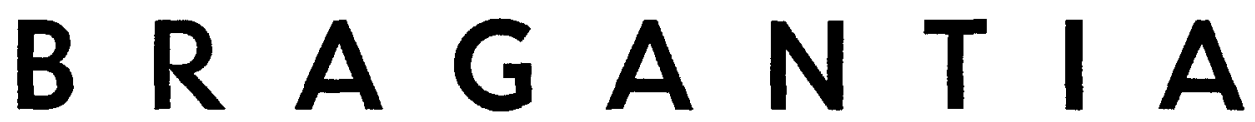

Revista Científica do Instituto Agronômico do Estado de São Paulo

Vol. 36

Campinas, outubro de 1977

N. ${ }^{\circ} 25$

\title{
GERMINAÇÃO DE SEMENTES DE ALGODOEIRO DESLINTADAS POR DIFERENTES MÉTODOS ( $(\mathbf{)}$
}

Jocely A. Maeda, Antônio A. do Lago $\left({ }^{2}\right)$, Eduardo Zink $\left({ }^{2}\right)$, Francisco C.

Krzyzanowski, Seção de Sementes, Edivaldo Cra $\left({ }^{2}\right)$, Francisco S. O. Rodrigues

Filho $\left({ }^{2}\right)$ e Carlos A. M. Ferraz $\left({ }^{2}\right)$, Seção de Algodão, Instituto Agronômico

\section{SINOPSE}

Sementes de algodāo do cultivar IAC 13-1 foram deslintadas por quatro diferentes métodos, a saber: mecanicamente, por ácido sulfúrico, por gás clorídrico e por flambagem. Após seleção em mesa de gravidade, cada porçãa relativa a um determinado método de deslintamento foi dividida em duas, sendo uma delas tratada com fungicida PCNB 75\%, nas dosagens recomendadas pelos fabricantes.

Após o teste inicial de germinaçāo, as sementes foram armazenadas em ambiente de laboratório e novos testes de germinaçáo foram feitos aos 3, 6 e 12 meses.

Em todos os períodos de armazenamento as porcentagens de germinacaão das sementes deslintadas por ácido sulfúrico e gás cloridrico foram superiores às das sementes deslintadas mecanicamente ou por flambagem que, por sua vez, foram iguais entre si ou com a flambagem ocupando posição intermediária. Em todos os períodos as porcentagens de germinação das sementes tratadas com fungicida foram superiores às das sementes sem esse tratamento.

\section{1 - INTRODUÇÃO}

O deslintamento da semente de algodoeiro visando facilitar o beneficiamento e o plantio pode ser feito por meios mecânicos, ácido, gás ou fogo $(4,13)$. A maior parte da semente de algodoeiro produzida no Brasil é deslintada mecanicamente (4); uma quantidade relativamente pęquena é deslintada a gás clorídrico (9). Os métodos de deslintamento por ácido e por fogo não são empregados em nosso País, tendo sido até agora apenas objeto de pesquisas.

De 1935 a 1938 , Costa e Santos Neto (3) realizaram ensaios testando

(1) Recebido para publicaçāo em 5 de janeiro de 1977.

(2) Com bolsa de suplementação do C.N.Pq. 
diversas formas de tratamento de sementes de algodoeiro. Eles concluíram que o deslintamento por ácido sulfúrico foi o mais vantajoso, fornecendo sementes de alto valor cultural, facilitando a semeadura, promovendo economia de sementes, apressando 'e uniformizando a germinação e atuando como uma desinfestação da semente.

Toledo \& Barbin (11), comparando sementes de algodoeiro deslintadas mecanicamente, à flama e quimicamente, observaram que as sementes deslintadas quimicamente apresentaram maior porcentagem de emergência no campo do que aquelas deslintadas à flama e mecanicamente.

Ferraz \& outros (5) estudaram comparativamente quatro métodos de deslintamento de sementes de algodão, em condições de campo, com e sem tratamento fungicida, em diversas localidades e anos agrícolas. Eles verificaram que os métodos de deslintamento por ácido sulfúrico e gás clorídrico proporcionaram maiores porcentagens de emergência no campo do que o método mecânico; o método por flambagem ocupou posição intermediária. Também houve efeito significativo de fungicida, conforme o método de deslintamento empregado.

$O$ efeito positivo de tratamento fungicida na germinação e emergência de sementes de algodoeiro tem sido comprovado por diversos autores entre os quais Abrahão \& outros (1), Haskell \& Barker 6), Simpson (10) e Maeda \& outros (8).

O presente trabalho teve por objetivo estudar o efeito sobre a germinação, de quatro métodos de deslintamento de sementes de algodoeiro, tratadas e não tratadas com fun- g1cida e armazenadas por 12 meses, em condições ambientes de laboratório, na região de Campinas, Estado de São Paulo.

\section{2 - MATERIAL E MÉTODOS}

Um lote de sementes de algodoeiro (Gossypium 'hirsutum L.) do cultivar IAC 13-1, produzidas no ano agrícola $1972 / 73$, após deslintamento mecânico foi dividido em quatro porções homogêneas, uma das quais permaneceu sem nenhum outro tipo de deslintamento e as outras três receberam, respectivamente, o deslintamento adicional pelo método do ácido sufúrico, do gás clorídrico e da flambagem.

No deslintamento mecânico as sementes, após descaroçadas, passaram por máquina deslintadeira (9). Esse tipo de deslintamento é o mais utilizado no Estado de São Paulo (4).

O deslintamento por ácido sulfúrico foi feito adicionando-se às sementes deslintadas mecanicamente ("sementes brancas") ácido sulfúrico comercial concentrado na proporção de um litro do ácido para três quilos de sementes, durante três minutos. Em seguida as sementes foram lavadas em água corrente até completa remoção do ácido, e postas a secar $(4,5)$.

As sementes destintadas por gás clorídrico foram obtidas por tratamento das "sementes brancas" com um gás ácido (ácido clorídrico anidro), obtido pela reação entre o ácido clorídrico e o ácido sulfúrico, em aparelhagem própria $(4,9)$.

$\mathrm{Na}$ flambagem, ou deslintamento pelo fogo, as "sementes brancas" fo- 
ram passadas três vezes em chama de maçarico, em equipamento do Laboratório de Sementes da Escola Superior de Agricultura "Luiz de Queiroz" $(4,5)$.

As sementes correspondentes a cada método de deslintamento foram selecionadas em mesa de gravidade, tendo havido um descarte médio de aproximadamente $8 \%$. Após isso, cada porção foi posteriormente dividida em duas, sendo uma delas tratada com fungicida PCNB $75 \%$ nas dosagens de $0,75 \%$ em peso para sementes deslintadas mecanicamente $e$ à chama, e $0,50 \%$ para aquelas deslintadas por ácido e gás.

Após teste inicial de germinação (2), as sementes foram armazenadas em ambiente de laboratório, e novos testes de germinação foram feitos aos 3,6 e 12 meses.

O experimento constou de um ensaio fatorial $4 \times 2$ inteiramente casualizado, com oito tratamentos $\mathrm{e}$ quatro repetições. $\mathrm{Na}$ análise esta- tística, feita por período, os dados de germinação foram transformados em arc sen $\sqrt{\%}$ e a comparação de médias feita pelo teste de Duncan.

\section{3 - RESULTADOS E DISCUSSÃO}

As porcentagens de germinação nos diversos períodos de armazenamento encontram-se no quadro 1 .

Em geral as porcentagens de germinação aos seis meses foram menores do que aos 12 meses; essa discrepância pode ser atribuída a indesejáveis variações nas condições ambientes do germinador, tornando-as pouco favoráveis à germinação das sementes, principalmente quando não tratadas. Toole \& Drummond (12) afirmaram que a semente de a!godão é mais sensível às condições de germinação do que as sementes da maioria das grandes culturas.

Inicialmente, independentemente do método de deslintamento empre-

QUADRO 1. - Resultados, em porcentagens, dos testes de germinação realizados em sementes de algodoeiro deslintadas por quatro métodos, com e sem tratamento fungicida e armazenadas por um período de 12 meses. Médias de quatro repetições

\begin{tabular}{|c|c|c|c|c|c|}
\hline \multirow{2}{*}{ Método de deslintamento } & \multirow{2}{*}{$\begin{array}{l}\text { Tratamento } \\
\text { fungicida }\end{array}$} & \multicolumn{4}{|c|}{ Meses de armazenamento } \\
\hline & & 0 & 3 & 6 & 12 \\
\hline & & $\%$ & $\%$ & $\%$ & $\%$ \\
\hline \multirow[t]{2}{*}{ Acido sulfúrico } & Com & 94 & 96 & 87 & 92 \\
\hline & Sem & 91 & 90 & 48 & 87 \\
\hline \multirow[t]{2}{*}{ Gás cloridrico } & Com & 92 & 92 & 90 & 89 \\
\hline & Sem & 82 & 86 & 54 & 73 \\
\hline \multirow[t]{2}{*}{ Flambagem } & Com & 77 & 79 & 69 & 74 \\
\hline & Sem & 68 & 73 & 30 & 41 \\
\hline \multirow[t]{2}{*}{ Mecânico } & Com & 76 & 71 & 69 & 78 \\
\hline & Sem & 55 & 52 & 43 & 43 \\
\hline
\end{tabular}


gado, as sementes tratadas com fungicida apresentaram germinação acima de 70\%. Em sementes não tratadas, somente aquelas deslintadas por ácido sulfúrico e gás clorídrico apresentaram germinação acima de $70 \%$. Resultados semelhantes ocorreram também aos três e 12 meses.
Em todos os períodos, inclusive aos seis meses, as sementes deslintadas por ácido sulfúrico e gás clorídrico e tratadas com fungicida apresentaram germinação acima de $80 \%$.

As médias dos resultados obtidos, transformadas em arc sen $\sqrt{\%}$ encontram-se no quadro 2 .

QUADRO 2. - Valores e significâncias de F, coefìcientes de variação e comparação de médias para deslintamento, fungicida $\mathrm{e}$ interaçäo deslintamento $\mathrm{x}$ fungicida relativos aos dados de germinação de sementes de algodoeiro armazenadäs por um período de 12 meses. Médias de quatro repetições $(x=\operatorname{arcsen} \sqrt{\%})$

\begin{tabular}{|c|c|c|c|c|}
\hline \multirow{2}{*}{ Fonte de variaçāo } & \multicolumn{4}{|c|}{ Meses de armazenamento } \\
\hline & $\mathbf{0}$ & 3 & 6 & 12 \\
\hline \multicolumn{5}{|l|}{ Deslintamento (D) } \\
\hline Ac. sulfúrico (As) & $74,1 a^{(1)}$ & $75,9 a$ & $56,1 \mathrm{a}$ & $71,3 \mathrm{a}$ \\
\hline Gás clorídrico (Gc) & $68,9 a$ & $70,6 a$ & $59,6 a$ & $65,0 \mathrm{a}$ \\
\hline Flambagem $(F b) \quad \ldots \ldots \ldots \ldots$ & $58,3 b$ & $60,8 b$ & $44,5 b$ & $49,5 b$ \\
\hline Mecânico (Mc) . & $54,5 \mathrm{~b}$ & $51,9 \mathrm{c}$ & $48,7 \mathrm{~b}$ & $51,5 \mathrm{~b}$ \\
\hline $\mathbf{F} \quad \ldots \ldots \ldots \ldots$ & $36,7 * *$ & $41,1 * *$ & $13,9 * *$ & $42,7 * *$ \\
\hline \multicolumn{5}{|l|}{ Fungicida (F) } \\
\hline Com $\ldots \ldots \ldots \ldots \ldots \ldots \ldots$ & 67,8 & 68,4 & 63,2 & 66,5 \\
\hline sem $\quad \ldots \ldots \ldots \ldots \ldots \ldots \ldots$ & 60,0 & 61,1 & 41,2 & 52,1 \\
\hline $\mathbf{F} \quad \ldots \ldots \ldots \ldots \ldots \ldots \ldots \ldots$ & 27,1 ** & $19,2 * *$ & 143,3 ** & $80,4^{* *}$ \\
\hline \multicolumn{5}{|l|}{$\mathbf{D} \times \mathbf{F}$} \\
\hline As - Com ... & - & - & - & $73,8 \mathrm{a}$ \\
\hline As - Sem $\ldots \ldots \ldots \ldots \ldots$ & - & - & - & $68,8 a b c$ \\
\hline $\mathrm{Gc}-\operatorname{Com} \ldots \ldots \ldots \ldots$ & - & - & - & $70,9 a b$ \\
\hline Gc $-\operatorname{sem} \ldots \ldots \ldots \ldots$ & - & - & - & $59,1 \mathrm{c}$ \\
\hline $\mathrm{Fb}-\mathrm{Com} \ldots \ldots \ldots \ldots \ldots$ & - & - & - & $59,4 c$ \\
\hline $\mathrm{Fb}-\operatorname{Sem} \ldots \ldots \ldots \ldots \ldots$ & - & - & - & $39,5 d$ \\
\hline $\mathrm{Mc}-\mathrm{Com} \ldots \ldots \ldots$ & - & - & - & $62,1 b c$ \\
\hline Mc $-\operatorname{sem} \ldots \ldots \ldots \ldots \ldots$ & - & 一 & - & $41,0 \mathrm{~d}$ \\
\hline $\mathbf{F} \quad \ldots \ldots \ldots \ldots \ldots \ldots \ldots \ldots$ & 1,9 n.s. & 1,0 n.s. & 1,5 n.s. & $5,4^{* *}$ \\
\hline C.V. $(\%) \quad \ldots \ldots \ldots \ldots$ & 6,6 & 7,2 & 10,0 & 7,8 \\
\hline
\end{tabular}

** Significativo ao nivel de $1 \%$

n.s. Não significativo

(1) Dentro de um mesmo periodo, letras não comuns indicam diferenças significativas ao nivel de $1 \%$ 
Estudando o quadro 2, observase que houve efeito significativo de método de deslintamento e tratamento fungicida em todos os períodos de armazenamento. Efeito significativo de interação deslintamento $\mathrm{x}$ fungicida só foi observado aos 12 meses.

Em todos os períodos as porcentagens de germinação das sementes deslintadas por ácido sulfúrico e gás clorídrico foram iguais entre si e superiores às porcentagens de germinação das sementes deslintadas pelos outros dois métodos que, por sua vez, foram iguais entre si ou com a flambagem ocupando posição intermediária. Tais observações confirmam, de modo geral, aquelas feitas por Ferraz \& outros ( 5 ), com relação à emergência no campo.

Em todos os períodos as porcentagens de germinação das sementes tratadas com fungicida foram superiores àquelas das sementes sem tratamento fungicida. Esses resultados concordam com os de Helmer (7) que, estudando os efeitos de diversos tipos de deslintamento combinados com tratamento fungicida, observou que as porcentagens de germinação em laboratório e no campo de sementes tratadas com fungicida foram, de modo geral, superiores às das sementes sem tratamento fungicida. No mesmo trabalho, o referido autor constatou que a emergência das se- mentes deslintadas por ácido sulfúrico foi superior à daquelas deslintadas à chama ou apenas descaroçadas.

Aos 12 meses, em sementes deslintadas por ácido sulfúrico, não houve diferença de germinação entre sementes tratadas e não tratadas com fıngicida. No mesmo período, em semcntes tratadas com fungicida, não houve diferença de germinação entre sementes deslintadas por gás clorídrico e mecanicamente.

\section{4 - CONCLUSŌES}

a) Em todos os períodos de armazenamento as porcentagens de germinação das sementes deslintadas por ácido sulfúrico e gás clorídrico foram superiores às das sementes deslintadas mecanicamente ou por flambagem que, por sua vez, foram iguais entre si ou com a flambagem ocupando posição intermediária.

b) Após 12 meses, as sementes deslintadas por ácido sulfúrico, com e sem tratamento fungicida, e por gás clorídrico com tratamento fungicida, apresentaram germinação acima de $80 \%$.

c) Em todos os períodos, as porcentagens de germinação das sementes tratadas com fungicida foram superiores às das sementes sem esse tratamento.

\section{GERMINATION OF COTTONSEED DELINTED BY DIFFERENT METHODS}

\section{SUMMARY}

The laboratory germination of mechanical-delinted, acid-delinted, gas-delinted, and flame-delinted cottonseed of the IAC 13-1 variety, treated and not treated with $a$ fungicide, was evaluated during a storage period of 12 months. 
In all the storage periods, acid-delinted and gas-delinted cottonseed provided higher germination percentages than those delinted by machine or by flame. In all the storage periods, fungicide-treated seeds of each type produced higher germination percentages than did untreated seed.

\section{LITERATURA CITADA}

1. ABRAHÃO, J.; BASTOS CRUZ, B. P. \& GREGORI, R. Tratamento das sementes de algodão como medida de controle das doenças das sementeiras. Biológico 30(7): :168-173, 1964.

2. BRASIL. Ministério da Agricultura. Escritório de Produção Vegetal. Equipe Técnica de Sementes e Mudas. Regras para Análise de Sementes. Brasilia, 1966. $120 \mathrm{p}$.

3. COSTA, A. S. \& SANTOS NETO, J. A. O deslintamento das sementes de algodão pelo ácido sulfúrico em comparação com outros tratamentos. Rev. Agr. (Piracicaba) XV (3-4):120-132, 1940.

4. FERRAZ, C. A. M. Produção de sementes de algodoeiro. Agronômico 27/28:154-197, $1975 / 6$.

5. - ; RODRIGUES FILHO, F. S. O.; CIA, E.; SABINO, N. P.; VEIGA, A. A.; REIS, A. J. \& ORTOLANI, D. B. Estudo comparativo de métodos de deslintamento de sementes de algodoeiro (Gossypium hirsutum L.). Bragantia 36:11-22, 1977.

6. HASKELL, R. J. \& BARKER, H. D. Cotton-seed treatment. Washington, D.C., U.S. Department of Agriculture, 1940. 7p. (U.S. Department of Agriculture Leaflet n. ${ }^{\circ}$ 198)

7. HELMER, J. Field and laboratory performance of cotton-seed processed by different methods. Mississippi State University, Mississippi State, Mississippi, 1965. 88p. (PhD thesis)

8. MAEDA, J. A.; LAGO, A. A.; KRZYZANOWSKI, F. C.; ORTOLANI, D. B.; RAZERA, L. F.; ZINK, E.; MATOS, M.; MADEIRA, A. A. \& USBERTI, R. Germinação de sementes de algodão tratadas com diversos fungicidas. Semente 2(2): 8-13, 1976.

9. RAZERA, L. F. Deslintamento da semente do algodoeiro (Gossypium hirsutum r. latifolium). Revisão bibliográfica. Piracicaba, Escola Superior de Agricultura "Luiz de Queiroz", 1976. 16p. (Mimeografado)

10. SIMPSON, D. M. The longevity of cottonseed as affected by climate and seed treatments. J. Am. Soc. Agron. 38:32-45, 1946.

11. TOLEDO, F. F. \& BARBIN, D. Estudos sobre sementes de algodoeiro deslintadas mecanicamente, à flama e quimicamente. In: Seminário Brasileiro de Sementes, $1 .^{\circ}$, Viçosa. Anais. Viçosa, Imprensa Universitária da Universidade Rural, 1968. p.6-13.

12. TOOLE, E. H. \& DRUMMOND, P. L. The germination of cottonseed. Jour. Agr. Res. 28(3):285-295, 1924.

13. WADDLE, B. M. \& COLWICK, R. F. Producing seeds of cotton and other fiber crops. In: The United States Department of Agriculture. Seeds, The Yearbook of Agriculture. Washington, D.C., U.S.D.A., 1961. p.188-192. 